\title{
PENGARUH POLA ASUH ORANG TUA TERHADAP PEMBENTUKAN KARAKTER ANAK DI DESA BUDIHARJA KECAMATAN CILILIN KABUPATEN BANDUNG BARAT
}

\author{
${ }^{1}$ Eneng Martini, ${ }^{2}$ Edi Kusnadi dan ${ }^{3}$ Andi Rahmat Tri Bagja \\ ${ }^{1}$ Program Studi PPKn Jurusan PIPS STKIP Pasundan \\ Email: eneng.martini13@gmail.com \\ ${ }^{2}$ Program Studi PPKn FKIP, Universitas Islam Nusantara \\ Email: edi.kusnadi@fkip-uninus.ac.id \\ ${ }^{3}$ Program Studi PPKn Jurusan PIPS STKIP Pasundan \\ Email: binter.rider@gmail.com
}

\begin{abstract}
The number of parents who are too busy with their work are like the elderly who live in the countryside where her daily livelihood is a farmer and keeps busy in the field to cultivate her plants from before the rising of the sun until the evening approaches, resulting in a lack of attention to her child. It is an intentional lack of interaction between parents and their children where almost the average work of parents in Budiharja Village, Cililin sub-district is a farmer. The purpose of this study is to know: To find out how much parents provide parenting to children, fostering the formation of children's character and the influence of parental care to the formation of children's character in the Village Budiharja Cililin District. This study uses a quantitative descriptive method that emphasizes the processing of numbers and questionnaires as the main instrument. The results of research generally conclude that all the variables simultaneously have a significant effect on the implementation of parenting pattern to the character formation of children. Based on the results of the analysis and discussion, the results of the questionnaire calculation that parents strongly disagree to physical violence $77.5 \%$ and $47 \%$ responded not agree to be hard to the child but the parents have given freedom to children. Parents always nurture the character of the child to fit the 18 characters of the nation, but they emphasize more on their children to be more religiously imitating the behavior of the Prophet Muhammad.
\end{abstract}

Keywords: character, parenting patterns

\begin{abstract}
ABSTRAK
Banyaknya orang tua yang terlalu sibuk terhadap pekerjaannya seperti orang tua yang tinggal dipedesaan yang mata pencaharian sehar-hari nya sebagai petani dan terus sibuk diladang mengurusi tanamannya dari sebelum terbit matahari sampai malam menjelang, sehingga kurangnya perhatian terhadap anaknya. Hal tersebut mengaktibatkan kurangnya interaksi antara orang tua dengan anaknya dimana hampir rata-rata pekerjaan orang tua di Desa Budiharja Kecamatan Cililin adalah seorang petani. Adapun tujuan penelitian ini adalah untuk mengetahui : Untuk mengetahui seberapa besar orang tua memberikan pola asuh kepada anak, memupuk pembentukan karakter anak dan pengaruh pola asuh orang tua terhadap pembentukan karakter anak di Desa Budiharja Kecamatan Cililin. Penelitian ini menggunakan metode kuantitatif deskritif yang lebih menekankan pada pengolahan angka dan angket sebagai instrumen utamanya. Hasil penelitian pada umumnya menyimpulkan bahwa seluruh variable secara bersama-sama (simultan)
\end{abstract}


berpengaruh signifikan terhadap implementasi pola asuh orang tua terhadap pembentukkan karakter anak. Berdasarkan hasil analisis dan pembahasan, hasil perhitungan angket bahwa orang tua sangat tidak setuju melakukan kekerasan fisik $77,5 \%$ dan $47 \%$ menjawab tidak setuju bersikap keras kepada anak melainkan orang tua sudah memberikan kebebasan kepada anak. Orang tua selalu memupuk karakter anak untuk sesuai dengan 18 karakter bangsa, tetapi mereka lebih menekankan kepada anaknya untuk lebih religius mencontoh tingkah laku Nabi Muhamad Saw.

\section{Kata Kunci: Pola asuh orang tua, Karakter}

\section{PENDAHULUAN}

Pola pengasuhan anak merupakan cara orang tua mengasuh anak mencakup dalam segi pengalaman, keahlian, kualitas, dan tanggung jawab yang dilakukan orang tua dalam mendidik dan merawat anak, sehingga anak dapat tumbuh menjadi pribadi yang diharapkan oleh keluarga dan dibutuhkan masyarakat dimana dia berada dan tinggal. Dalam penelitian awal yang peneliti temui banyaknya orang tua yang terlalu sibuk terhadap pekerjaannya seperti orang tua yang tinggal dipedesaan yang mata pencaharian sehar-harinya sebagai petani dan terus sibuk diladang mengurusi tanamannya dari sebelum terbit matahari sampai malam menjelang, sehingga kurangnya perhatian terhadap anaknya. Hal tersebut mengaktibatkan kurangnya interaksi antara orang tua dengan anaknya dimana hampir rata-rata pekerjaan orang tua di Desa Budiharja Kecamatan Cililin adalah seorang petani. Kurangnya interaksi orang tua dengan anak yang kerap membuat mereka sering terkena masalah, pada masa kanak-kanak adalah waktu yang tepat untuk mendidik dan menjadikan anak tersebut menjadi apa yang orang tua dan masyarakat butuhkan, tetapi karena kurangnya pengasuhan, terbatasnya waktu bersama dan kurangnya interaksi antara anak dengan orang tualah yang menyebabkan anak sulit diatur. penelitian ini bertujuan untuk mengetahui seberapa besar orang tua memberikan pola asuh kepada anak, memupuk pembentukan karakter anak dan pengaruh pola asuh orang tua terhadap pembentukan karakter anak di Desa Budiharja Kecamatan Cililin.

\section{Pola Asuh Orang Tua}

Menurut Hasan (2009:21) "Secara etimologi, pengasuhan berasal dari kata "asuh" yang artinya pemimpin, pengelola, pembimbing, sehingga pengasuhan adalah orang yang melaksanakan tugas membimbing, memimpin, atau mengelola”. Hal ini juga diterangkan oleh Djamarah (2014:51) "bahwa pola asuh orang tua, ayah dan atau ibu, dalam memimpin, mengasuh dan membimbing anak dalam keluarga". Pengasuhan yang dimaksudkan disini adalah mengasuh anak. Mengasuh anak adalah mendidik dan memelihara anak seperti mengurus makannya, minumnya, pakaiannya, dan keberhasilannya dalam periode yang pertama sampai dewasa. Dengan pengertian tersebut, dapat dipahami bahwa pengasuhan anak yang dimaksud adalah kepemimpinan dan bimbingan yang dilakukan terhadap anak yang berkaitan dengan kepentingan hidupnya. Djamarah (2014:51) membagi beberapa pola asuh dari 
orang tua/pendidik yang dapat mempengaruhi anak adalah sebagai berikut : Lingkungan fisik, Lingkungan sosial ,Pendidikan internal dan eksternal, Dialog,Suasana psikologis, Sosial budaya, Perilaku orang tua/pendidik, Kontrol, Menentukan nilai moral. Kesembilan pola asuh orang tua/pendidik tersebut sangat mempengaruhi perkembangan diri dan pengembangan kreativitas anak didalam kehidupannya.

Model pola asuh atau model kepemimpinan yang dikemukakan oleh Widjaja (dalam Djamarah 2014:56-58) ada beberapa model pola asuh orang tua yang dirasa perlu untuk di ambil tetapi hanya sebagian, yaitu :

a. Model Pola

Kepemimpinan antara pemimpin dan pengikut.

Pola ini sebagai hubungan yang erat antara seorang pemimpin dan pengikut.

b. Model Pola Kepemimpinan Ki Hajar Dewantara

Pola kepemimpinan ini adalah ing ngarso sung tulodo, ing madyo mangun karso, tut wuri handayani.

c. Model Kepemimpinan Pancasila

Pola kepemimpinan ini mengikuti pola seimbang, selaras dan serasi menurut situasi dan kondisi (sikon).

Pola asuh orang tua dalam keluarga tampil dalam berbagai tipe, ada 15 macam tipe pola asuh orang tua dalam keluarga menurut Djamarah (2014:60), yaitu :

a. Gaya Otoriter, Tipe pola asuh ini adalah tipe pola asuh orang tua yang selalu memaksakan kehendak orang tua kepada anaknya.

Tipe pola asuh ini cenderung sebagai pengendali dan pengawas (controller), selalu memkasakan kehendak, tidak terbuka terhadap anak, sangat sulit menerima saran, terlalu percaya pada diri sendiri sehingga menutup katub musyawarah.

b. Gaya Demokrasi, Tipe pola asuh ini adalah tipe pola asuh yang terbaik dari semua tipe pola asuh yang ada. Hal ini disebabkan karena tipe pola asuh ini selalu mendahulukan kepentingan bersama diatas kepentingan individu anak.

c. Gaya Laissez-faire, tipe pola asuh ini tidak berdasarkan aturan-aturan, kebebasan memilih terbuka bagi anak dengan sedikit campur tangan orang tua agar kebebasan yang diberikan terkendali.

d. Gaya Fathernalistik, pola asuh ini adalah pola asuh kebapaan, dimana orang tua bertindak sebagai ayah terhadap anak dalam perwujudan mendidik, mengasuh, mengajar, membimbing dan menasehati.

e. Gaya Karismatik, tipe pola asuh ini adalah pola asuh orang tua yang memiliki kewibawaan yang kuat.

f. Gaya Melebur Diri, tipe pola asuh ini adalah tipe pola asuh yang mengedepankan keharmonisan hubungan 
dan membangun

kerjasama dengan anak dengan cara menggabungkan diri.

g. Gaya Pelapor, tipe pola asuh ini biasanya orang tua selalu ada didepan sebagai pelapor untuk memberikan contoh atau suri tauladan dalam kebaikan bagi anak dalam keluarga.

h. Gaya Manipulasi, tipe pola asuh ini adalah tipe pola asuh orang tua yang selalu berbohong, tidak sesuai dengan kenyataan, dan memutarbalikan fakta.

i. Gaya Transaksi, tipe pola asuh ini adalah selalu melakukan perjanjian (transaksi) dimana antara orang tua dengan anak membuat kesepakatan dari setiap tindakan yang diperbuat.

j. Gaya Biar Lambat Asal Selamat, tipe pola asuh ini adalah tipe pola asuh yang sangat behati-hati dalam mengambil dan bertindak.

k. Gaya Alih Peran, tipe pola asuh ini adalah tipe pola asuh yang mendelegasikan wewenang dan tanggung jawab kepada anak.

1. Gaya Pamrih, tipe pola asuh ini adalah tipe pola asuh yang apabila orang tua ingin menggerakan anaknya untuk melakukan sesuatu maka ada imbalan jasanya dalam bentuk material.

m. Gaya Tanpa Pamrih, tipe pola asuh ini kebalikan dari pola asuh Gaya Pamrih, karena dalam tipe pola asuh ini orang tua mengajarkan ke ikhlasan kepada anaknya dalam berprilaku dan berbuat.

n. Gaya Konsultan, tipe pola asuh ini adalah orang tua yang bertindak sebagai tempat anak untuk menceritakan keluh kesahnya. Dalam tipe pola asuh ini terbentuk dua komunikasi dan orang tua sangat terbuka kepada anak, mempunyai banyak waktu untuk anak.

o. Gaya Militeristik, tipe pola asuh ini adalah orang tua yang selalu memerintah, tanpa dialog anak harus mematuhi perintahnya. Tidak boleh di bantah, harus tunduk dan taat pada perintah dan larangan.

Berdasarkan pendapat diatas, dapat ditarik kesimpulan bahwa dari beberapa banyak tipe pola asuh orang tua tenyata kebanyakan hanya memaksakan kehendak orang tua kepada anaknya dan tidak memberikan kebebasan hak memilih anak. Pola asuh yang dipilih, diberikan dan diterapkan kepada anak sangat penting bagi perkembangan anak dalam berbagai segi seperti bertingkah laku, berbicara, gaya hidup, dan lain sebagainya.

\section{Pembentukan Karakter}

Pembentukan adalah usaha yang telah terwujud sebagai hasil suatu tindakan. Karakter berasal dari bahasa yunani yaitu "kharrasein" yang berarti memahat atau mengukir (to inscribelto engrave), sedangkan menurut Narwanti (2011:11) "dalam bahasa latin, karakter bermakna membedakan tanda, sifat kejiwaan, tabiat, dan watak". Menurut Sjarkawi (2006:1) "Karakter adalah ciri atau 
karakteristik atau gaya atau sifat khas dari diri seseorang yang bersumber dari bentukan-bentukan yang diterima dari lingkungan, misalnya keluarga pada masa kecil, dan juga bawaan seseorang sejak lahir".

Sedangkan menurut Narwanti (2011:3) "Karakter adalah suatu sifat yang tertanam dalam jiwa seseorang dan sifat itu akan timbul disetiap ia bertindak tanpa merasa sulit (timbul dengan mudah) karena sudah menjadi budaya sehari-hari”. Menurut Parwez (dalam Yaumi 2010:7-8) definisi karakter dapat dijabarkan sebagai berikut :

a. Moralitas adalah Karakter. Karakter merupakan sesuatu yang terukir dalam diri seseorang.

b. Karakter adalah manifestasi kebenaran, dan kebenaran adalah penyesuaian kemunculan pada realitas.

c. Karakter adalah mengadopsi kebaikan dan kebaikan adalah gerakan menuju suatu tempat kediaman. Kejahatan adalah perasaan gelisah yang tiada berujung dari potensialitas manusia

\section{Tabel 1}

Nilai-nilai Karakter dan Budaya Bangsa

\begin{tabular}{|c|c|}
\hline \multicolumn{2}{|c|}{$\begin{array}{l}\text { Tabel } 1 \\
\text { Nilai-nilai Karakter dan Budaya Bangsa }\end{array}$} \\
\hline NILAI & DESKRIPSI \\
\hline Religius & $\begin{array}{l}\text { Sikap dan perilaku yang patuh dalam melaksanakan } \\
\text { ajaran agama yang dianutnya, toleran terhadap } \\
\text { pelaksanaan ibadah agama lain, dan hidup rukun } \\
\text { dengan pemeluk agama lain. }\end{array}$ \\
\hline Jujur & $\begin{array}{l}\text { Perilaku yang didasarkan pada upaya menjadikan } \\
\text { dirinya sebagai orang yang selalu dapat dipercaya } \\
\text { dalam perkataan, tindakan, dan pekerjaan. }\end{array}$ \\
\hline Toleransi & $\begin{array}{l}\text { Sikap dan tindakan yang menghargai perbedaan } \\
\text { agama, suku, etnis, pendapat, sikap, dan tndakan orang } \\
\text { lain yang berbeda dari dirinya. }\end{array}$ \\
\hline Disiplin & $\begin{array}{l}\text { Tindakan yang menunjukan perilaku tertib dan patuh } \\
\text { pada berbagai ketentuan dan peraturan. }\end{array}$ \\
\hline Kerja Keras & $\begin{array}{l}\text { Perilaku yang menunjukan upaya sungguh-sungguh } \\
\text { dalam mengatasi berbagai hambatan belajar dan tugas, }\end{array}$ \\
\hline
\end{tabular}

tanpa sesuatu yang dapat dicapai, jika tidak mengambil arah namun tetap juga terjebak dalam ketidak tahuan, dan akhirnya semua sirna.

d. Karakter adalah memiliki kekuatan terhadap diri sendiri; karakter adalah kemenangan dari penghambaan terhadap diri sendiri.

e. Dalam pengertian yang lebih umum, karakter adalah sikap manusia terhadap lingkungannya yang diekspresikan dalam tindakan.

Dari definisi karakter di atas, maka dapat dikatakan bahwa karakter adalah moralitas, kebenaran, kebaikan, kekuatan, dan sikap seseorang yang ditunjukan kepada orang lain melalui tindakan. Karakter seseorang dikatakan baik apabila sesuai dengan norma atau aturan yang berlaku pada masyarakat, negara maupun bangsa. Berikut adalah tabel karakter yang baik menurut Character count (dalam Yaumi, 2014:60) : 


\begin{tabular}{|c|c|}
\hline & serta menyelesaikan tugas dengan sebaik-baiknya. \\
\hline Kreatif & $\begin{array}{l}\text { Berpikir dan melakukan sesuatu untuk menghasilkan } \\
\text { cara atau hasil baru dari sesuatu yang sudah dimiliki. }\end{array}$ \\
\hline Mandiri & $\begin{array}{l}\text { Sikap dan perilaku yang tidak mudah tergantung pada } \\
\text { orang lain dalam menyelesaikan tugas-tugas. }\end{array}$ \\
\hline Demokratis & $\begin{array}{l}\text { Cara berpikir, bersikap, dan bertindak yang menilai } \\
\text { sama hak dan kewajiban dirinya dan orang lain. }\end{array}$ \\
\hline Rasa Ingin Tahu & $\begin{array}{l}\text { Sikap dan tindakan yang selalu berupaya untuk } \\
\text { mengetahui lebih mendalam dan meluas dari sesuatu } \\
\text { yang dipelajarinya, dilihat, dan didengar. }\end{array}$ \\
\hline Semangat kebangsaan & $\begin{array}{l}\text { Cara berpikir, bertindak, dan berwawasan yang } \\
\text { menempatkan kepentingan bangsa dan negara diatas } \\
\text { kepentingan diri dan kelompoknya. }\end{array}$ \\
\hline Cinta Tanah Air & $\begin{array}{l}\text { Cara berpikir, bersikap, dan berbuat yang menujukan } \\
\text { kesetiaan, kepedulian, dan penghargaan yang tinggi } \\
\text { terhadap bahasa, lingkungan fisik, sosial, budaya, } \\
\text { ekonomi, dan politik bangsa. }\end{array}$ \\
\hline Menghargai Prestasi & $\begin{array}{l}\text { Sikap dan tindakan yang mendorong dirinya untuk } \\
\text { menghasilkan sesuatu yang berguna bagi masyarakat, } \\
\text { dan mengakui, serta menghormati keberhasilan orang } \\
\text { lain. }\end{array}$ \\
\hline Bersahabat/komuniktif & $\begin{array}{l}\text { Tindakan yang memperlihatkan rasa senang berbicara, } \\
\text { bergaul, dan bekerja sama dengan orang lain. }\end{array}$ \\
\hline Cinta Damai & $\begin{array}{l}\text { Sikap, perkataan, dan tindakan yang menyebabkan } \\
\text { orang lain merasa senang dan aman atas kehadiran } \\
\text { dirinya. }\end{array}$ \\
\hline Gemar Membaca & $\begin{array}{l}\text { Kebiasaan menyediakan waktu untuk membaca } \\
\text { berbagai bacaan yang memberikan kebajikan bagi } \\
\text { dirinya. }\end{array}$ \\
\hline Peduli Lingkungan & $\begin{array}{l}\text { Sikap dan tindakan yang selalu berupaya mencegah } \\
\text { kerusakan pada lingkungan alam disekitarnya, dan } \\
\text { mengembangkan upaya-upaya untuk memperbaiki } \\
\text { kerusakan alam yang sudah terjadi. }\end{array}$ \\
\hline Peduli Sosial & $\begin{array}{l}\text { Sikap dan tindakan yang selalu ingi memberi bantuan } \\
\text { pada orang lain dan masyarakat yang membutuhkan. }\end{array}$ \\
\hline Tanggung Jawab & $\begin{array}{l}\text { Sikap dan perilaku seseorang untuk melaksanakan } \\
\text { tugas dan kewajibannya, yang seharusnya dia lakukan, } \\
\text { terhdap diri sendiri, masyarakat, lingkungan (Alam, } \\
\text { sosial, dan Budaya), Negara dan Tuhan Yang Maha } \\
\text { Esa. }\end{array}$ \\
\hline
\end{tabular}

Jadi kesimpulannya pola asuh orang tua adalah suatu bentuk atau model pengasuhan dan pendidikan orang tua kepada anaknya agar anaknya berprilaku baik, sedangkan karakter adalah suatu sifat yang ada dalam diri seseorang yang terbentuk atau masih bisa dibentuk dalam pergaulan sehari-hari. Pola asuh orang tua sangatlah berpengaruh terhadap karakter anaknya karena apabila orang tua salah dalam 
mendidik anaknya maka anaknya belum tentu bisa berprilaku dengan baik.

\section{Hipotesis Penelitian}

Berdasarkan teori di atas, maka hipotesis yang diajukan sebagai berikut: Terdapat pengaruh positif dan signifikan antara pola asuh orang tua terhadap pembentukan karakter anak di Desa Budiharja Kecamatan Cililin Kabupaten Bandung Barat.

\section{METODE}

Penelitian ini menggunakan metode kuantitatif deskritif yang lebih menekankan pada pengolahan angka dan angket sebagai instrumen utamanya. Dapat dikatakan bahwa penelitian kuantitatif adalah suatu penelitian yang memerlukan pengujian hipotesis untuk mengukur setiap variabel yang ada dengan jumlah populasi yang besar, sehingga memerlukan adanya sampel serta menggunakan statistik dalam menganalisis temuannya.

\section{Objek penelitian}

Penelitian ini dilakukan di Lingkungan sekitar rumah pada anak-anak di Desa Budiharja Kecamatan Cililin Kabupaten Bandung Barat. Mengingat populasi sasaran penelitian jumlahnya cukup banyak, maka pengambilan sample dilakukan dengan menggunakan teknik sample simple random sampling, yang dijadikan sample pada penelitian ini adalah anak anak yang ada di Desa Budiharja Kecamatan Cililin sebanyak 40 Orang.

\section{Desain Penelitian}

Untuk menentukan sebuah desain penelitian biasanya disesuaikan dengan jenis pendekatan atau metode penelitian yang digunakan

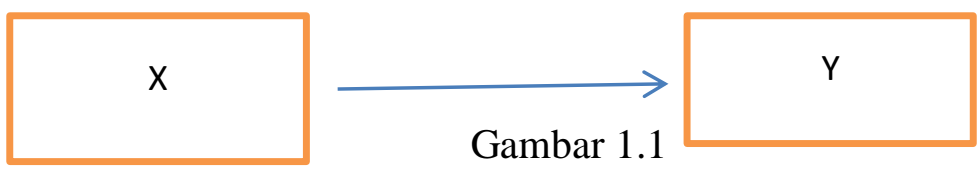

Desain Penelitian

Keterangan :

1. Variabel Bebas (X), Pola Asuh

2. Variabel Terikat (Y), Karakter anak

\section{Teknik Pengumpulan Data}

Teknik pengumpulan data yang digunakan dalam melaksanakan penelitian adalah sebagai berikut:

A. Studi Kepustakaan, yaitu mempelajari buku-buku atau bahan-bahan tertulis yang ada hubungannya dengan penelitian yang dilakukan.

B. Studi lapangan, yaitu pengumpulan data yang langsung terjun ke lapangan dengan cara sebagai berikut:

a. Observasi, yaitu suatu teknik pengumpulan data yang dilakukan melalui pengamatan lapangan terhadap obyek penelitian.

b. Wawancara, yaitu suatu teknik pengumpulan data dengan mengadakan Tanya jawab

c. Angket, yaitu suatu teknik pengumpulan data primer guna menguji hipotesis yang dilakukan melalui tanggapan, opini dan sikap respon. 


\section{Uji Validitas dan Reliabilitas}

Pengujian selanjutnya penulis menentukan uji validitas dan uji reliabilitas guna menghasilkan data yang valid sehingga dibutuhkan pengujian validitas dan reliabilitas pada data yang akan disebarkan. Adapun uraian pengujian dapat diketahui sebagai berikut.

\section{Uji Validitas}

Untuk menguji validitas instrumen, peneliti menggunakan rumus korelasi Product moment

$$
\begin{aligned}
& r_{x y} \\
& =\frac{\mathrm{n} \sum \mathrm{xy}-\left(\sum X\right)\left(\sum Y\right)}{\left.\sqrt{\left(n \sum x^{2}\right.}-\left(\sum X\right)^{2}\right)\left(n \sum y^{2}-\left(\sum Y\right)^{2}\right)}
\end{aligned}
$$

Sugiyono (2012:259)

Keterangan :

rxy $=$ koefisien korelasi sutau butir

$$
\begin{array}{ll}
\mathrm{N} & =\text { jumlah responden } \\
\mathrm{X} & =\text { skor butir } \\
\mathrm{Y} & \text { = skor butir }
\end{array}
$$

Menurut

Sugiyono (2013:357), jika hasil uji memberikan nilai koefisien korelasi $>0,312 \quad(\mathrm{n}=40)$ maka instrumen tersebut dinyatakan valid sebaliknya jika nilai koefisien korelasi $<0,312$ maka instrumen tersebut dinyatakan tidak valid. Berikut merupakan hasil uji instrumen pernyataan

\section{Uji Reliabilitas}

Reliabilitas adalah suatu teknik untuk mengetahui apakah alat pengukur dapat mengukur dengan hasil yang sama saat digunakan beberapa kali. Untuk mengetahui reliabiltas instrumen, penulis menggunakan rumus Spearman brown sebagai berikut:

$$
r_{\mathrm{i}}=\frac{2 r b}{1+r b}
$$

\section{Dimana}

$r_{\mathrm{i}}=$ reliabilitas internal seluruh instrumen.

$\mathrm{rb}=$ korelasi product moment antara belahan pertama dan kedua.

\section{Uji Korelasi}

Uji Korelasi dilakukan untuk mengetahui kuat atau lemahnya hubungan antara variabel. Uji korelasi didapatkan dengan rumus korelasi product moment

$$
=\frac{r_{x y}}{\left.\sqrt{\left(n \sum x^{2}\right.}-\left(\sum X\right)^{2}\right)\left(n \sum y^{2}-\left(\sum Y\right)^{2}\right)}
$$

Keterangan :

$r_{x y}:$ koefisien korelasi yang dicari

$\mathrm{N}$ : jumlah responden

$\sum X \quad$ : jumlah skor $\mathrm{X}$

$\sum \mathrm{Y}$ : jumlah skor $\mathrm{Y}$

$\sum X Y$ : jumlah hasil kali dari $\mathrm{X}$ dan $\mathrm{Y}$

$\sum \mathrm{X}^{2} \quad$ : jumlah kuadrat dari variabel

$\sum_{Y} \mathrm{y}^{2} \quad$ jumlah kuadrat dari variabel

\section{Mencari signifikasi}

Kriteria uji validitas dapat diketahui dengan melakukan uji signifikasi untuk mengetahui validitas setiap item soal. Uji signifikasi dihitung dengan menggunakan uji t, yaitu:

$$
t=\frac{r \sqrt{n-2}}{\sqrt{1-r^{2}}}
$$

Keterangan :

$\mathrm{t}=$ hasil perhitungan uji signifikasi

$\mathrm{n}=$ banyaknya peserta tes.

$\mathrm{r}=$ validitas tes.

kemudian hasil perolehan thitung dibandingkan dengan ttabel pada taraf kepercayaan 95\% $\quad(a=0,05)$ dengan derajat kebebasab $(\mathrm{dk})=\mathrm{n}-2$. 
Apabila thitung $>$ ttabel, maka item soal dinyatakan valid. Dan apabila thitung $<\mathrm{t}$ tabel, maka item soal dinyatakan tidak valid.

\section{HASIL DAN PEMBAHASAN PENELITIAN \\ Kondisi Desa}

Desa Budiharja Kecamatan Cililin merupakan desa yang berada di wilayah Cililin yang termasuk di daerah kawasan Bandung Barat Selatan dimana mata pencaharian mayoritas bercocok tanam sifatnya tadah hujan dan pengrajin anyaman bambu, Data lain menerangkan bahwa, nama Budiharja dicetuskan pada tahun 1982 ketika ada persiapan pemekaran desa, nama Budiharja terdiri atas dua kata yaitu "Budi" dan

\section{Mengetahui indeks determinasi}

Rumus

ID $=r^{2} X 100 \%$

\begin{abstract}
"Raharja" dengan pengertian "Budi" (pekerti) "Raharja" (sejahtera) dengan maksud memakai nama Budiharja bertujuan agar masyarakat desa Budiharja berbudi luhur dan sejahtera yang cukup sandang, pangan, papan.
\end{abstract}

Secara Geografis Desa Budiharja terletak didaerah kawasan Bandung Barat Selatan, dengan luas wilayah 348,344 Hektar yang terdiri dari 3 dusun dan 12 rukun warga dan 45 rukun tetangga.

Dengan batas wilayah sbb :

\section{Tabel 2}

Batas Wilayah

\begin{tabular}{|l|l|l|}
\hline Batas & Desa/ Kelurahan & Kecamatan \\
\hline Sebelah Utara & Mekarmukti & Cihampelas \\
\hline Sebelah Selatan & Batulayang/Bongas & Cililin \\
\hline Sebelah Timur & Cililin & Cililin \\
\hline Sebelah Barat & Karang Anyar & Cililin \\
\hline
\end{tabular}

\section{Topografi Desa Budiharja dikelilingi oleh genangan PLTA} merupakan desa yang berada di Saguling. lereng gunung Gegerpulus sebelah selatan, dengan ketinggian 600-700 Mdpl (Diatas Permukaan Laut), Aspek hidrologi suatu wilayah desa sangat diperlukan dalam pengendalian dan pengaturan tata air diwilayah desa, wilayah desa Budiharja merupakan desa yang

\section{Deskripsi Hasil Penelitian dan Pembahasan}

Perhitungan korelasi dan signifikasi korelasi mengenai Pengaruh pola asuh orang tua terhadap pembentukan karakter anak di Desa Budiharja Kecamatan Cililin Kabupaten Bandung Barat adalah sebagai berikut :

Tabel 3

Perhitungan Korelasi Variabel $X$ dan $Y$

\begin{tabular}{|c|c|c|c|c|c|}
\hline Sampel & $X$ & $Y$ & $X^{2}$ & $Y^{2}$ & $X Y$ \\
\hline 1 & 26 & 24 & 676 & 576 & 624 \\
\hline 2 & 49 & 66 & 2401 & 4356 & 3234 \\
\hline 3 & 62 & 64 & 3844 & 4096 & 3968 \\
\hline 4 & 65 & 63 & 4225 & 3969 & 4095 \\
\hline 5 & 68 & 72 & 4624 & 5184 & 4896 \\
\hline 6 & 70 & 66 & 4900 & 4356 & 4620 \\
\hline
\end{tabular}




\begin{tabular}{|c|c|c|c|c|c|}
\hline 7 & 82 & 70 & 6724 & 4900 & 5740 \\
\hline 8 & 68 & 65 & 4624 & 4225 & 4420 \\
\hline 9 & 72 & 68 & 5184 & 4624 & 4896 \\
\hline 10 & 75 & 67 & 5625 & 4489 & 5025 \\
\hline 11 & 74 & 69 & 5476 & 4761 & 5106 \\
\hline 12 & 77 & 76 & 5929 & 5776 & 5852 \\
\hline 13 & 81 & 74 & 6561 & 5476 & 5994 \\
\hline 14 & 71 & 73 & 5041 & 5329 & 5183 \\
\hline 15 & 79 & 74 & 6241 & 5476 & 5846 \\
\hline 16 & 84 & 75 & 7056 & 5625 & 6300 \\
\hline 17 & 76 & 72 & 5776 & 5184 & 5472 \\
\hline 18 & 83 & 81 & 6889 & 6561 & 6723 \\
\hline 19 & 79 & 69 & 6241 & 4761 & 5451 \\
\hline 20 & 77 & 78 & 5929 & 6084 & 6006 \\
\hline 21 & 77 & 71 & 5929 & 5041 & 5467 \\
\hline 22 & 78 & 72 & 6084 & 5184 & 5616 \\
\hline 23 & 70 & 68 & 4900 & 4624 & 4760 \\
\hline 24 & 73 & 67 & 5329 & 4489 & 4891 \\
\hline 25 & 71 & 69 & 5041 & 4761 & 4899 \\
\hline 26 & 78 & 68 & 6084 & 4624 & 5304 \\
\hline 27 & 78 & 65 & 6084 & 4225 & 5070 \\
\hline 28 & 74 & 74 & 5476 & 5476 & 5476 \\
\hline 29 & 79 & 70 & 6241 & 4900 & 5530 \\
\hline 30 & 70 & 74 & 4900 & 5476 & 5180 \\
\hline 31 & 73 & 77 & 5329 & 5929 & 5621 \\
\hline 32 & 73 & 77 & 5329 & 5929 & 5621 \\
\hline 33 & 78 & 79 & 6084 & 6241 & 6162 \\
\hline 34 & 74 & 71 & 5476 & 5041 & 5254 \\
\hline 35 & 77 & 70 & 5929 & 4900 & 5390 \\
\hline 36 & 77 & 75 & 5929 & 5625 & 5775 \\
\hline 37 & 70 & 66 & 4900 & 4356 & 4620 \\
\hline 38 & 74 & 78 & 5476 & 6084 & 5772 \\
\hline 39 & 65 & 68 & 4225 & 4624 & 4420 \\
\hline 40 & 75 & 71 & 5625 & 5041 & 5325 \\
\hline Jumlah & 2902 & 2796 & 214336 & 198378 & 205604 \\
\hline
\end{tabular}

$$
r_{x y} \frac{\mathrm{n} \sum \mathrm{xy}-\left(\sum X\right)\left(\sum Y\right)}{\left.\sqrt{\left(n \sum x^{2}\right.}-\left(\sum X\right)^{2}\right)\left(n \sum y^{2}-\left(\sum Y\right)^{2}\right)}
$$

40.205604-(2902)(2796)

$$
\begin{aligned}
& =\frac{8224160-8113992}{\sqrt{40.214336-(842164)(40.198378-(7817616)}} \\
& =\frac{8 \sqrt{(8573440-8421604)(7935120-789809)}}{\sqrt{(150168}} \\
& =\frac{11036)(117504)}{\sqrt{(15168}}=\frac{110168}{133571,46905}=0,824
\end{aligned}
$$

Hasil Perhitungan Korelasi Variabel Bebas (X) dan Variabel
Terikat (Y) Pengaruh pola asuh orang tua terhadap pembentukan 
karakter anak di Desa Budiharja Kecamatan Cililin Kabupaten Bandung Barat adalah sebesar 0,824 dan hasil uji hasil korelasi sebesar 8,957. Harga t- hitung di atas dikonsultasikan dengan tabel distribusi $\mathrm{t}$ dengan signifikasi 0,05 dan derajat kebebasan $\mathrm{dk}=\mathrm{n}-2,40-2$ $=38$, sehingga diperoleh t-tabel $=1,684$. Jadi Keputusannya : Karena t-hitung 8,951 maka $\mathrm{H}_{\mathrm{o}}$ ditolak maka Kesimpulan : Terdapat hubungan yang signifikasi antara variabel $\mathrm{X}$ dengan variabel $Y$. Untuk perhitungan determinasi mendapatkan koefisien Pengruh/koefisien determinasi sebesar $67,8 \%$.

Lickona (1992) terjemahan Wahyudin (2012:49) menyebutkan para orang tua yang memberikan moral yang efektif berdasarkan indikasi penelitian adalah mereka yang autoratif membimbing anakanak untuk patuh kepada mereka. Sebaliknya orang tua yang permisif (yang enggan membuat aturan dan lebih bersikap mengancam terhadap penyimpangan yang terjadi) maupun orang tua yang authoritarian (orang tua yang banyak mengontrol anak tetapi tanpa memberikan alasan yang jelas terhadap aturan yang berlaku cenderung bersifat kaku) menunjukkan hasil yang sama yaitu keduanya tidak memberikan dampak yang baik bagi anak anak di segala usia dalam meningkatkan sikap pengendalian diri dan memunculkan anak anak yang memiliki tanggung jawab secara sosial.

Sementara menurut Dewantara (1962) dalam Komalasari (2017:21)

\section{DAFTAR REFERENSI}

Aqib, Z., \& sujak. (2011). Panduan danAplikasi Pendidikan Karakter. Bandung: Yrama Widya. strategi pendidikan karakter metode yang cocok dengan karakter dan budaya Indonesia tidak memakai syarat paksaan. Orang Indonesia termasuk ke dalam bangsa timur. Bangsa yang hidup dalam khasanah nilai-nilai tradisional berupa kehalusan rasa, hidup dalam kasih sayang, cinta akan kedamaian, ketertiban, kejujuran, dan sopan dalan tutur kata dan tindakan. Nilai nilai itu disemai dalam dan melalui usia sejak dini.

\section{SIMPULAN}

Orang tua di Desa Budiharja Kecamatan Cililin Kabupaten Bandung Barat hampir semuanya peduli dan memberikan pola asuh yang sebaik-baiknya terbukti dari hasil perhitungan angket bahwa orang tua sudah sangat tidak setuju melakukan kekerasan fisik $77,5 \%$ dan $47 \%$ menjawab tidak setuju bersikap keras kepada anak melainkan orang tua sudah memberikan kebebasan kepada anak. Orang tua selalu memupuk karakter anak untuk sesuai dengan 18 karakter bangsa, tetapi mereka lebih menekankan kepada anaknya untuk lebih religius mencontoh tingkah laku Nabi Muhamad Saw.

Pola asuh orang tua sangat berpengaruh terhadap pembentukan karakter anaknya terbukti dari hasil perhitungan dengan menggunakan rumus korelasi dan didapatkan hasil dengan signifikasi 0,05 dan derajat kebebasan $\mathrm{dk}=\mathrm{n}-2, \quad 40-2=38$, sehingga diperoleh $\mathrm{t}$-tabel $=1,684$ sehingga menunjukan hasil yang signifikan variabel $\mathrm{X}$ berpengaruh terhadap variabel $\mathrm{Y}$.

Djamarah, S. B. (2014). Pola Asuh Orang Tua dan Komunikasi dalam Keluarga. Jakarta: PT Rineka Cipta. 
Hasan, M. (2009). Pendidikan Anak Usia Dini. Jogjakarta: Diva Press.

Komalasari, Kokom. (2017). Pendidikan Karakter Konsep dan Aplikasi Living Values education, Bandung: Rfika Aditama.

Lickona, Thomas. (1992) Educating For Character Mendidik untuk membentuk Karakter bagaimana Sekolah dapat memberikan Pendidikan tentang Sikap Hormat dan Tanggung Jawab.

Terjemahan ,Uyu, Wahyudin
(2012), Bandung: Bumi Aksara.

Narwanti, S. (2011). Pendidikan

Karakter Pengintegrasian 18

Nilai dalam Mata

Pembelajaran. Yogyakarta:

Familia.

Sjarkawi. (2006). Pembentukan

Kepribadian Anak. Jakarta:

Bumi Aksara.

Sugiyono. (2012). Metode Penelitian Kuantitatif kualitatif dan $R \& D$. Bandung: Alfabeta.

Yaumi, M. (2014). Pendidikan

Karakter. Jakarta:

Prenadamedia Group. 